\title{
Benign stricture of the oesophagus: role of non-steroidal anti-inflammatory drugs
}

\author{
W E WILKINS, M G RIDLEY, AND A L POZNIAK
}

From the Royal United Hospital, Bath

SUMMARY The medication history of patients presenting with benign oesophageal stricture is compared with an age and sex matched control population selected from the community. Fifty five out of 151 consecutive admissions to a dysphagia clinic were found to have benign oesophageal stricture. Twenty six out of $53(49 \%)$ had been prescribed non-steroidal anti-inflammatory drugs in the year preceding their clinic appointment. Ten patients (19\%) had been prescribed other drugs implicated in oesophageal disease over the same period. In the control population, 20 out of $165(12 \%)$ had been prescribed non-steroidal anti-inflammatory drugs, and 31 out of 165 had been prescribed 'other' drugs in the preceding year. The difference between numbers on non-steroidal anti-inflammatory drugs in the patient and control groups was highly significant $\left(\chi^{2}=23 \cdot 87, \mathrm{p}<0 \cdot 1 \%\right)$. This study has shown an association between the prescribing of non-steroidal anti-inflammatory drugs and benign stricture of the oesophagus.

Gastro-oesophageal reflux is the most important cause of oesophageal ulceration. The relationship between gastro-oesophageal reflux and benign oesophageal stricture is less clearly defined: only a minority of patients with radiographic and endoscopic evidence of reflux oesophagitis progress to benign stricture. This suggests that there are other factors involved in the progression to stricture formation.

There are a number of publications which question the role of certain drugs in the aetiology of benign stricture. ${ }^{1-4}$ The majority relate to case reports, but Heller and colleagues ${ }^{5}$ in a controlled study found a significant association between a history of non-steroidal anti-inflammatory drug ingestion and benign oesophageal stricture.

In the following study, the medication history of patients presenting at a dysphagia clinic with benign oesophageal stricture is compared with that of a control population selected from the community.

\section{Methods}

PATIENTS

Consecutive admissions to the dysphagia clinic over

Address for correspondence: W E Wilkins. Bridgend General Hospital. Bridgend. Mid-Glamorgan.

Received for publication 22 July 1983 an 18 month period have been studied. Fifty five out of $151(36.4 \%)$ patients, referred from 33 general practice groups, had benign oesophageal stricture as defined by barium radiograph, endoscopy, and biopsy. The age range was $40-95$ years, mean 73.9 years $(S D \pm 14)$ and there were 29 men and 26 women $(1: 1 \cdot 1)$. Thirty three out of the 55 patients $(60 \%)$ gave a history of dyspepsia. Forty five patients $(82 \%)$ had radiographic evidence of hiatus hernia, and 52 patients $(94.5 \%)$ endoscopic evidence of oesophagitis.

Five patients out of the 55 gave a history of medical disorder or of a surgical procedure which could be implicated in the cause of oesophageal stricture. Two had rheumatoid disease, and three had undergone repair of hiatus hernia.

The control group was selected from general practice age and sex registers. Each patient was matched with a control subject of the same sex and of a similar age. The maximum differences in ages between patient and matched control was 18 months. To account for differences in prescribing practice, three general practice groups were used. Thus, each patient was matched with three controls.

The nature and duration of prescribed medication for the patient and control was recorded for the year preceding the date of the dysphagia clinic appointment. To ensure accuracy of information the details of drugs prescribed were extracted from 
general practice records.

Statistical method as the $\chi^{2}$ test for independence of variables. $p<5 \%$ was considered significant.

\section{Results}

\section{STRICTURE GROUP}

A complete drug history as obtained in 53 out of the 55 patients. Twenty six (49\%) had been prescribed non-steroidal anti-inflammatory drugs for periods of at least six weeks in the year preceding their clinic appointment. The type of non-steroidal antiinflammatory drug is listed in Table 1 . Indomethacin was the most commonly prescribed drug.

Ten out of the 53 patients $(19 \%)$ had been prescribed other drugs which have been implicated in oesophageal disease. Three out of the 10 were also on non-steroidal anti-inflammatory drugs (Table 2).

Table 3 documents the frequency of dyspeptic complaints in the period immediately before presentation, and the prevalence of hiatus hernia and oesophagitis at the time of presentation. There was no significant difference between patients who had and who had not been prescribed non-steroidal anti-inflammatory drugs.

CONTROL GROUP

A complete drug history was obtained in all subjects. Twenty out of the $165(12 \%)$ had been prescribed non-steroidal anti-inflammatory drugs for periods of at least six weeks in the preceding year (Table 4).

Thirty one patients $(19 \%)$ had been prescribed other drugs which could be implicated in oesophageal mucosal damage. Five of these patients

Table 1 Type of non-steroidal anti-inflammatory drug prescribed

\begin{tabular}{lll}
\hline & $\begin{array}{l}\text { Stricture Group } \\
(n=53)\end{array}$ & $\begin{array}{l}\text { Control group } \\
(n=165)\end{array}$ \\
\hline Aspirin & 2 & 5 \\
Indomethacin & $11(20.7 \%)$ & $5(3.0 \%)^{*}$ \\
Ibuprofen (Brufen) & $5(9 \cdot 4 \%)$ & $2(1 \cdot 2 \%)$ \\
Phenylbutazone & 2 & 0 \\
Flurbiprofen (Froben) & 1 & 2 \\
Ketoprofen (Alrheumat) & 1 & 0 \\
Mefenamic acid (Ponstan) & 1 & 0 \\
Fenbufen (Lederfen) & 1 & 0 \\
Diclofenac (Voltarol) & 1 & 0 \\
Azapropazone (Rheumox) & 1 & 0 \\
Fenoprofen (Fenopron) & 0 & 3 \\
Diflunisal (Dolobid) & 0 & 1 \\
Naproxen (Naprosyn) & 0 & 1 \\
Piroxicam (Feldene) & 0 & 1 \\
\hline
\end{tabular}

* Difference was significant using $\chi^{2}$ test of independence $(p=4 \%)$.
Table 2 Relationship between oesophageal stricture, nonsteroidal anti-inflammatory drugs and other ${ }^{*}$ drugs

\begin{tabular}{lllll}
\hline & $\begin{array}{l}\text { On } \\
N S A I \\
(n=26)\end{array}$ & $\begin{array}{l}\text { Not on } \\
\text { NSAI } \\
(n=27)\end{array}$ & $\begin{array}{l}\text { On } \\
\text { NSAI } \\
(n=25)\end{array}$ & $\begin{array}{l}\text { Not on } \\
\text { NSAI } \\
(n=140)\end{array}$ \\
\hline Potassium compounds & 2 & $5^{+}$ & 3 & 25 \\
Vit C compounds & $2 \dagger$ & 0 & 2 & 1 \\
Tetracyclines & 0 & 3 & 0 & 0 \\
\hline
\end{tabular}

* Drugs previously implicated in oesophageal ulceration.

† One patient had been on two 'other' drugs.

were also on non-steroidal anti-inflammatory drugs (Table 2).

During the period of search (records for one year) three control subjects presented to their general practitioners with dyspepsia; all were on nonsteroidal anti-inflammatory drugs. One patient with benign stricture came from the general practice groups used in the selection of the control population.

\section{STATISTICAL INTERPRETATION}

There was a highly significant difference $\left(\chi^{2}=32 \cdot 9\right.$, $p<0.1 \%$ ) between the numbers on non-steroidal anti-inflammatory drugs in the patient group (26 out of 53) compared with the control group (20 out of $165)$.

If patients with a rheumatoid, surgical, or 'other drug' history are excluded, then 19 out of the 38 patients with peptic stricture gave a history of non-steroidal anti-inflammatory ingestion: the difference between the control and patient groups remains significant $\left(\chi^{2}=28 \cdot 1, p<0 \cdot 1 \%\right)$.

Table 3 Dyspepsia, oesophagitis and hiatus hernia in the stricture group

\begin{tabular}{llll}
\hline & $\begin{array}{l}\text { Hiatus hernia } \\
\text { (endoscopic } \\
\text { and/or barium } \\
\text { radiograph }\end{array}$ & $\begin{array}{l}\text { Oesophagitis } \\
\text { (endoscopy) }\end{array}$ & $\begin{array}{l}\text { Dyspepsia } \\
\text { (previous } \\
\text { 6 months) }\end{array}$ \\
\hline $\begin{array}{l}\text { Patients on } \\
\text { NSAI drugs } \\
\text { (n=26) }\end{array}$ & 25 & 25 & 14 \\
$\begin{array}{l}\text { Patients on } \\
\text { other drugs* } \\
\text { (n=7) }\end{array}$ & 6 & 7 & 5 \\
$\begin{array}{c}\text { Patients not on } \\
\text { culpable drugs } \\
\text { (n=19) }\end{array}$ & 17 & 18 & 13 \\
\hline
\end{tabular}

${ }^{*}$ Drugs previously implicated in oesophageal damage. NSAI = non-steroidal anti-inflammatory. 
Table 4 Age, sex, dyspeptic history and clinical joint disease

\begin{tabular}{|c|c|c|c|c|c|c|c|}
\hline & & \multicolumn{6}{|c|}{ Patients and controls (no.) } \\
\hline & & $\begin{array}{l}\text { Age } \\
(y r)\end{array}$ & $\begin{array}{l}\text { Sex } \\
M: F\end{array}$ & $\begin{array}{l}\text { Dyspepsia } \\
\text { (last } 6 \text { months) }\end{array}$ & $\begin{array}{l}\text { Other } \\
\text { drugs* }\end{array}$ & Osteoarthritis & $\begin{array}{l}\text { Rheumatoid } \\
\text { arthritis }\end{array}$ \\
\hline \multirow{2}{*}{$\begin{array}{l}\text { Stricture } \\
\text { group } \\
(n=53)\end{array}$} & $\begin{array}{l}\text { On NSAI drugs } \\
(\mathrm{n}=26) \\
\text { Not on }\end{array}$ & $74 \cdot 7 \pm 7 \cdot 5$ & $12: 14$ & $14(54 \%)$ & 3 & $16(61 \%)$ & 2 \\
\hline & $\begin{array}{l}\text { NSAI drugs } \\
(\mathrm{n}=27)\end{array}$ & $72 \cdot 4 \pm 7 \cdot 5$ & $16: 11$ & $18(67 \%)$ & 7 & 1 & 0 \\
\hline \multirow{3}{*}{$\begin{array}{l}\text { Control } \\
\text { group } \\
(n=165)\end{array}$} & On NSAI drugs & $76 \cdot 2 \pm 7 \cdot 9$ & $7: 13$ & $3(15 \%)$ & 5 & $18(90 \%)$ & 1 \\
\hline & $\begin{array}{l}(n=20) \\
\text { Not on }\end{array}$ & & & & & & \\
\hline & $\begin{array}{l}\text { NSAI drugs } \\
(n=145)\end{array}$ & $75 \cdot 13 \pm 9 \cdot 4$ & $81: 64$ & $12(8 \cdot 3 \%)$ & 26 & 6 & 0 \\
\hline
\end{tabular}

* Drugs previously implicated in oesophageal damage.

NSAI = non-steroidal anti-inflammatory.

\section{Discussion}

Oesophageal mucosal damage is probably the initiating factor in benign oesophageal stricture. Gastro-oesophageal reflux is, almost certainly, the commonest cause of damage to the oesophageal mucosa, and yet only a minority of such patients will develop benign stricture. The absence of a definitive relationship between gastro-oesophageal reflux and stricture formation suggests that there may be other 'catalytic' factors.

This study has shown an association between the prescribing of non-steroidal anti-inflammatory drugs and benign oesophageal stricture. A number of the stricture patients were also on other drugs previously implicated in oesophageal mucosal damage, but no significant difference was seen on comparing these with the control population. The majority of patients with stricture had radiographic and endoscopic evidence of hiatus hernia and endoscopic evidence of oesophagitis. No difference in frequency of dyspeptic complaints, prevalence of hiatus hernia and of oesophagitis was seen on comparing patients who had been on non-steroidal anti-inflammatory drugs with those who had not.

Thus, the relationship between non-steroidal antiinflammatory drugs and benign oesophageal stricture is not simple. Oesophageal reflux and oesophagitis obviously enter into the equation, and possibly the individual's susceptibility to mucosal injury. Age must also be a factor; the average age of patients referred consecutively with benign stricture was 73.9 years. The prevalence of oesophageal dysmotility increases with ageing, ${ }^{67}$ and it is possible that stasis increases the potential of nonsteroidal anti-inflammatory drugs to damage mucosa.
The results of this study add support to the findings of Heller and colleagues. Caution should be exercised in prescribing non-steroidal antiinflammatory drugs to patients with a history to suggest oesophageal reflux, particularly if elderly.

We would like to thank Dr K R Gough for his help and advice in the preparation of this manuscript, $\mathrm{Dr}$ Francis Duck for his advice on statistical interpretation, and Mrs S J Willis and Miss G Morgan for secretarial help.

\section{References}

1 Howie AD, Strachan RW. Slow release potassium chloride treatment. Br Med J 1975; 2: 176.

2 Walter DC, Giddens JD, Johnson LF, Keeley JL, Waugh DF. Localised proximal esophagitis secondary to ascorbic acid ingestion and esophageal motor disorder. Gastroenterology 1976; 70: 766-9.

3 Crowson TD. Head LH. Ferrante WA. Esophageal ulcers associated with tetracycline therapy. JAMA 1976; 235: 2747-8.

4 Kavin H. Oesophageal ulceration due to emepronium bromide. Lancet 1977; 1: 424-5.

5 Heller SR, Fellows IW, Ogilvie AL, Atkinson M. Non-steroidal anti-inflammatory drugs and benign oesophageal stricture. $B r$ Med J 1982; 285: 167-8.

6 Zboralske FF, Amberg JR, Soergel KH. Presbyesophagus: cineradiographic manifestations. Radiology 1964; 88: 463-7.

7 Alikhan T, Shragge BW, Crispin JS, Lind JF. Esophageal motility in the elderly. Dig Dis 1977; 22: 1049-54. 